\title{
O Grau Zero e o Engajamento Fracassado EM LIMA BARRETO*
}

\author{
The degree zero and the failed engagement in Lima \\ Barreto
}

\author{
Keli Cristina Pacheco*
}

\begin{abstract}
[...] pode-se conceder à literatura um valor essencialmente interrogativo; [...] admiravelmente servido por aquele sistema decepcionante que, ao meu ver, constitui a literatura, o escritor pode então ao mesmo tempo engajar profundamente sua obra no mundo, nas perguntas do mundo, mas suspender esse engajamento precisamente ali onde as doutrinas, os partidos, os grupos e as culturas lhe sopram uma resposta.
\end{abstract}

Roland Barthes ${ }^{1}$

A espera de um possível, de um topos por vir, parece uma boa definição da noção de literatura que Lima Barreto toma para si em seus discursos. Escritor de romances, novelas, sátiras, inúmeros contos e crônicas que publicava em jornais marginais do Rio de Janeiro no início do século $\mathrm{XX}$, teve alguns de seus escritos não terminados, uma vez que a morte $o$ leva muito cedo, aos 41 anos, pouco depois da semana de arte moderna de 1922, considerada um marco do modernismo no Brasil. Negro, de origem humilde, a mãe falecera quando ainda era pequeno, logo depois enlouquece seu pai. O escritor cedo se torna "arrimo de família", sustenta os irmãos e ainda trabalha como amanuense na Secretaria da Guerra.

Lima Barreto sempre insistiu que pretenderia, através da literatura, romper os limites que separam os homens, sejam territoriais, ideológicos

Para este artigo, tomamos pequenos trechos do discurso "O destino da literatura"; o prefácio intitulado "Amplius!"; e os romances Triste Fim de Policarpo Quaresma e Vida e Morte de M. J. Gonzaga de Sá.

Mestre em Literatura pela Universidade Federal de Santa Catarina - UFSC. Pesquisadora bolsista de doutorado Capes na mesma universidade.

BARTHES, Roland. Literatura e Significação. In: Crítica e Verdade. 3. ed. Tradução de: Leila Perrone-Moisés. São Paulo: Perspectiva, 1999. Coleção Debates. p. 74. (Itálicos do autor). 
ou físicos ${ }^{2}$. Por não crer no sentido rígido de algumas classificações políticosociais, o escritor, em vida, não se limitou a nenhuma delas, lia autores marxistas e anarquistas, simpatizava com algumas posturas, mas não se engajou a causa alguma, somente se comprometia com a literatura, por acreditar que ela era um meio de fazer-nos...

[...] tudo compreender; entrando no segredo das vidas e das coisas, a Literatura reforça o nosso natural sentimento de solidariedade com os nossos semelhantes, explicando lhes os defeitos, realçando lhes as qualidades e zombando dos fúteis motivos que nos separam uns dos outros. Ela tende a obrigar a todos nós a nos tolerarmos e a nos compreendermos; e, por aí, nós nos chegaremos a amar mais perfeitamente na superfície do planeta que rola pelos espaços sem fim $^{3}$.

Há, notadamente em seus discursos, a crença na linguagem, na literatura como desencadeadora de uma comoção que possibilitaria a futura existência de uma comunidade por vir, daí poderíamos apontar uma utopia na escritura de Lima Barreto. Percebe-se que seu engajamento, se for possível usar esta palavra, não é puro e simples, não toma para si uma ideologia ou causa política, mas se alarga para uma proposta, digamos, mais humanitária, porém não escapa de sugerir a existência de um projeto que desencadearia numa tentativa de intervenção no real. Tal projeto propõe, de certo modo, uma transformação, uma espécie de morte para um renascimento de uma nova comunidade. Tal utopia significa, faz sentido. Segundo Roland Barthes: "A utopia é familiar ao escritor, porque o escritor é um doador de sentido: sua tarefa (ou seu gozo) consiste em dar sentidos, nomes [...], a utopia consiste então em imaginar uma sociedade infinitamente parcelada, cuja divisão não fosse mais social e, portanto, não fosse mais conflituosa" ${ }^{4}$.

2 Cf. escreve: "não sendo patriota, querendo mesmo o enfraquecimento do sentimento de pátria, sentimento exclusivista e mesmo agressivo, para permitir o fortalecimento de um maior, que abrangesse, com a terra, toda a espécie humana [...]". BARRETO, Lima. Bagatelas.

Obras Completas. São Paulo: Brasiliense, 1956. v. IX. p. 152. Poderíamos ver até a escritura dita "desleixada" do escritor, que se opõe à escritura parnasiana, como uma não aceitação da vinculação da escrita ao Estado. No ensaio "Concedamos a Liberdade de Traçar", no livro Rumor da Língua, Barthes propõe que a sociedade aceite desvincular a escrita do aparelho de Estado. A ortografia legalizada não permite ao escritor traçar a palavra com um pouco mais, restringe-o a forma, a fronteira da lei ortográfica, que fortalece a fronteira do Estado. Ver BARTHES, Roland. Concedamos a Liberdade de Traçar. In: $O$ Rumor da Língua. Tradução de: Mario Laranjeira. São Paulo: Brasiliense, 1988. p. 60.

BARRETo, Lima. O destino da literatura. In: Obras Completas de Lima Barreto. São Paulo: Brasiliense, 1956.

4 BARTHES, Roland. Para que serve a utopia. In: Roland Barthes por Roland Barthes. Tradução de: Leyla Perrone-Moisés. São Paulo: Cultrix. p. 84-85. 
A escritura ficcional deveria aparecer, então, como um lugar que aponta para um possível. Contudo, como desenhos de rostos inacabados, as personagens de seus romances, sempre exiladas, perambulam pelas narrativas e só encontram, ao fim, a morte e/ou a frustração ${ }^{5}$. É impossível não ver o desencanto generalizado em muitos de seus enredos ${ }^{6}$. Daí cabe uma pergunta: em Lima Barreto há contradição ou coerência entre sua escritura ficcional e a fala sobre a escritura?

Entretanto, antes ainda, é preciso esclarecer que, por uma perspectiva mais barthesiana, o poder de intervenção da literatura como instrumento de lutas ou causas resultaria nulo, quer dizer, a partir dela, da literatura, é impossível se obter alguma forma de engajamento. Roland Barthes nos ensina que por ser linguagem, matéria trabalhada, a literatura faz do real somente um pretexto, pois existe uma distância entre a língua e o real que provoca o irrealismo na ficção literária ${ }^{7}$. Sendo assim, a literatura passa a ser "o próprio irreal; mais exatamente, longe de ser uma cópia analógica do real, a literatura é pelo contrário a própria consciência do irreal da linguagem: a literatura mais verdadeira é aquela que se sabe mais irreal". Para Barthes a obra mais realista é aquela que "servindo-se do mundo como conteúdo, explorará o mais profundamente possível a realidade irreal da linguagem".

Ou seja, "a literatura nunca pode explicar o mundo"9. Sendo, num senso de sacralidade e crença do real, considerada uma "linguagem segunda",

5 Para fins de exemplo, adiantamos que em Triste Fim de Policarpo Quaresma o protagonista morre descobrindo que tudo o que perseguiu durante a vida (a pátria) de fato era uma construção humana sem lógica. Em Vida e Morte de M. J. Gonzaga de Sá a morte leva a personagem-título, que teve uma vida cheia de frustrações. Em Recordações do Escrivão Isaías Caminha, o protagonistanarrador acaba decepcionado, pois, para poder sobreviver, aceita um trabalho medíocre, cercado de falsidades, que o faz abandonar seu verdadeiro projeto de vida. Em Clara do Anjos, Clara, a personagem-título, ao fim da novela, chega à conclusão de que "não é nada nesta vida".

6 Como exemplo, Silviano Santiago, no ensaio "Uma ferroada no peito do pé", comenta sobre o fim triste de Policarpo: "O pessimismo visceral do pensamento de Lima Barreto aflora [...]; o nosso Policarpo nada deixa de si, daí a ironia maior de seu nome". Santiago supõe uma postura pessimista de Lima Barreto, como argumento, é usada uma interpretação dos sentidos do nome Policarpo Quaresma. "Policarpo" é, entre outras acepções exploradas pelo crítico, aquele que dá frutos. Mas, para Silviano Santiago há, sobretudo, ironia neste nome. "Quaresma", por sua vez, diz ele, significa penitência, uma espécie de coqueiro, além de um tipo de parasita. "É tanto o sinal que indica o caminho em vão do bode expiatório, como ainda o símbolo romântico por excelência da brasilidade ufanista que é o coqueiro". SANTIAGO, Silviano. Uma ferroada no peito do pé. In: Vale quanto pesa. São Paulo: Paz e Terra, 1982. p. 174.

Além disso, a própria existência do real deve ser questionada, uma vez que "não o conhecemos nunca senão sob a forma de efeitos (mundo físico), de funções (mundo social) ou de fantasmas (mundo cultural); em suma, o real nunca é ele próprio mais do que uma inferência". BARTHES, Roland. A literatura hoje. In: Crítica e Verdade. 3. ed. Tradução de: Leila PerroneMoisés. São Paulo: Perspectiva, 1999. Coleção Debates. p. 78.

8 BARTHES, Roland. A literatura hoje. In: Crítica e Verdade. 3. ed. Tradução de: LeilaPerrone Moisés. São Paulo: Perspectiva, 1999. Coleção Debates. p. 79.

9 BARTHES, Roland. Escritores e Escreventes. In: Crítica e Verdade. 3. ed. Tradução de: Leila Perrone-Moisés. São Paulo: Perspectiva, 1999. Coleção Debates. p. 33. 
uma vez que possui um sentido parasita, a literatura somente pode "conotar o real, não denotá-lo: o logos aparece irremediavelmente cortado da práxis; impotente para realizar a linguagem, isto é, ultrapassá-la em direção a uma transformação do real" ${ }^{10}$. Entretanto, a ficção é uma "trapaça salutar [...], [pois se] reconhece que a língua é um imenso halo de implicações, de efeitos, de repercussões, de voltas de rodeios, de redentes". E ao se admitir a "inadequação da linguagem ao real", segundo Barthes, a literatura tornase realista ${ }^{11}$. Assim parece ser que, por este motivo, a literatura pode instaurar perguntas, como nos ensinou Barthes na epígrafe, e como demonstra, muito anteriormente e com todas as ressalvas de seu espaço-tempo próprio, concordar Lima Barreto:

Parece-me que o nosso dever de escritores sinceros e honestos é deixar de lado todas as velhas regras, toda a disciplina exterior dos gêneros e aproveitar de cada um deles o que puder e procurar, conforme a inspiração própria, para tentar reformar certas usanças, sugerir dúvidas, levantar julgamentos adormecidos $[\ldots]^{12}$.

Para sugerir dúvidas é necessário não se limitar a causas, grupos, doutrinas ou culturas. Se, em seus discursos, o escritor tende a propor um fim, ir a um topo, operar um topos, uma finalidade funcional, à literatura; já na sua escritura romanesca há um constante levantar de questões que acreditamos estarem permeando disfunções. Disfunções tais que abalam a procura hegemônica da comunidade operante, quer dizer, como noção assentada em limites fixos, fronteiras simbólicas, territórios dados, assim por diante. Tomemos, a título de exemplo, Triste Fim de Policarpo Quaresma ${ }^{13}$ em que a personagem Quaresma sai em busca da "essência" da pátria e somente encontra, ao fim, o vazio e a morte. Sabidamente, nesse romance aparece enfim uma crítica contundente ao nacionalismo romântico, já que não apenas denuncia o absurdo do processo de idealização da pátria, mas

10 BARTHES, Roland. Literatura e Significação. In: Crítica e Verdade. 3. ed. Tradução de: Leila Perrone-Moisés. São Paulo: Perspectiva, 1999. Coleção Debates. p. 172. No ensaio "Literatura e Metalinguagem", a literatura aparece como "uma máscara que se aponta com o dedo", o que significa dizer que a literatura é aquela que reflete sobre si, que faz do exterior o interior. Quando se descobre que o real é uma máscara, a literatura então funciona como espelho. Cf. BARTHES, Roland. Literatura e Metalinguagem. In: Crítica e Verdade. 3. ed. Tradução de: Leila PerroneMoisés. São Paulo: Perspectiva, 1999. Coleção Debates. p. 29. p. $20-23$.

1 BARTHES, Roland. Aula. Tradução de: Leyla Perrone-Moisés. São Paulo: Cultrix, 1978. 1990. p. 11 .

BARreto, Lima. Amplius!. In: Prefácio - Histórias e Sonhos. Rio de Janeiro: Garnier,

13 Publicado em folhetins pelo Jornal do Comércio, do Rio de Janeiro, entre 11 de agosto e 19 de outubro de 1911. Cinco anos depois é lançado em volume. Considerado por muitos críticos como sendo um romance central da obra do autor. 
aponta para um questionamento da própria idéia de nação, ressaltando seu caráter de "comunidade imaginada" ${ }^{14}$. Vemos em Triste Fim... que a pátria não passa de uma construção humana fundada pela exclusão que, quando olhada desapaixonadamente, revela uma considerável descontinuidade, tanto no que diz respeito à configuração do próprio território que ocupa, quanto ao caráter, costumes e práticas das pessoas que habitam esse território ${ }^{15}$.

Ao fim do romance, Policarpo Quaresma chega a uma espécie de "grau zero", quando vê a pátria como uma "ausência que significa" ${ }^{16}$, um nada que adquire significado através de discursos e símbolos que, de fato, são esvaziados ${ }^{17}$.

14 Leitura feita também por Roberto Vecchi, quando afirma que "através da construção romanesca, Lima Barreto opera a desmontagem do aparato metafórico da nação imaginada pela elite e sedimentada desde a colônia nas representações edênicas da brasiliana despotencializando, sem ressentimento histórico mas com a argúcia crítica e prática estética, o artifício ideológico, os falsos mitos, o pseudo sentimentalismo patriótico, da localização ufanista do estado-nação". VECCHI, Roberto. Raízes do Brasil e a insustentável leveza do passado que não passa: sentimento e ressentimento modernistas. In: BRESCIANI, Stela; NAXARA, Márcia (Orgs.). A insustentável leveza do passado que não passa: sentimento e ressentimento modernistas. São Paulo: UNICAMP, 2001. p. 460 .

15 No artigo Em busca da terra prometida, Vera Figueiredo, acrescenta: "Ao associar a nação a um Deus, Lima Barreto chama a atenção para o fato de que o nacionalismo não é uma ideologia abraçada racionalmente e que, ao voltar-se para a criação de novas formas de lealdades humanas, para um novo modo de vincular fraternidade, vinha preencher a lacuna deixada pelas crenças pré-modernas, inclusive pela imaginação religiosa que a secularidade racionalista abalou a partir do século XVIII. Daí o questionamento de Policarpo Ouaresma, no final do livro, quanto à consistência racional da noção de pátria, percebendo que, de um determinado ângulo, o nacionalismo não resiste à reflexão crítica. A nação não seria uma comunidade que se estende na história e que possui uma (sic.) caráter distintivo natural". FIGUEIREDO, Vera Follain de. Em busca da terra prometida. In: ANDRADE, A. L.; CAMARGO, M. L. B.; ANTELO, R. (Orgs.) Leituras do Ciclo. Santa Catarina: Grifos, 1999. p. 243.

16 BARTHES, Roland. Elementos de Semiologia. 15. ed. Tradução de: Izidoro Blikstein. São Paulo: Cultrix, 2003. p. 81. Para compreender a noção de grau zero é interessante lembrar o ensaio "Literatura e Descontínuo", em que Barthes escreve sobre Móbile, de Michel Butor, que pode ser definido como um livro que fere a idéia de livro. Tendo como tema a América, apresenta os Estados da União "na mais insípida das ordens, que é a ordem alfabética". Como toda classificação engaja, o alfabeto dá-se como "um meio de institucionalizar-se o grau zero das classificações; nós nos espantamos com isso porque nossa sociedade sempre deu um privilégio exorbitante aos signos plenos e confunde grosseiramente o grau zero das coisas com sua negação BARTHES, Roland. Literatura e Descontínuo. In: Crítica $e$ Verdade. São Paulo: Perspectiva. p. 116. A ordem alfabética une descontínuos, é uma possibilidade de mundo, ou de uma compossibilidade. E é isto que Móbile nos apresenta, a compossibilidade de um novo continente. Porém é um novo com o antigo, pois esse catálogo da América, segundo Barthes, dialoga com aqueles catálogos épicos que "Homero e Ésquilo dispuseram em sua narrativa com o fim de testemunhar da infinita 'compossibilidade'da guerra e do poder". Ibid., p. 124.

${ }^{17}$ Barthes nos ensina que "a Doxa também não gosta do sentido, culpado, a seus olhos, de trazer para a vida uma espécie de inteligível infinito (que não se pode deter): à invasão do sentido (de que são responsáveis os intelectuais), ela opõe o concreto; o concreto é aquilo que se supõe resistente ao sentido". Entenda-se como concreto, por exemplo, as instituições. BARTHES, Roland. A isenção de sentido. In: Roland Barthes por Roland Barthes. Tradução de: Leyla PerroneMoisés. São Paulo: Cultrix. p. 94. 


\begin{abstract}
A pátria que quisera ter era um mito; era um fantasma criado por ele no silêncio do seu gabinete. [...] E, bem pensado, mesmo na sua pureza, o que vinha a ser Pátria? Não teria levado toda a sua vida norteado por uma ilusão, por uma idéia a menos, sem base, sem apoio, por um Deus ou uma Deusa cujo império se esvaía? Não sabia que essa idéia nascera da amplificação da crendice dos povos greco-romanos de que os ancestrais mortos continuariam a viver como sombras e era preciso alimentá-las para que eles não perseguissem os descendentes?

Reviu a história; via as mutilações, os acréscimos em todos os países históricos e perguntou de si para si: como um homem que vivesse quatro séculos sendo francês, inglês, italiano, alemão, podia sentir a Pátria?

Uma hora, para o francês, o Franco-Condado era terra dos seus avós, outra não era; num dado momento, a Alsácia não era, depois era e afinal não vinha a ser.

Nós mesmos não tivemos a Cisplatina e não a perdemos; e, porventura, sentimos que haja lá manes dos nossos avós e por isso sofremos qualquer mágoa?

Certamente era uma noção sem consistência racional e precisava ser revista ${ }^{18}$.
\end{abstract}

Policarpo Quaresma sente-se desencaixado. Era um utópico, acreditava na materialidade, na carne, da mãe-pátria, e, paulatinamente, no decurso de suas frustrações, se desencaixa desta utopia: a pátria tão perseguida deixa de ser um sonho, uma vez que se impossibilita realizar, e resulta num "fantasma". Está, a personagem, assombrada pela fantasmática da pátria, a aparição da pátria como desaparição, a transmaterialidade da pátria. A aparição da desaparição, por assim dizer. Convém, deste modo, pensar na metáfora do fantasma. Em alguns momentos de Barthes, o fantasma é co-relacionado, precisamente, ao duplo, e não a um topos almejado. Estar em contato com o fantasma é vislumbrar a impossibilidade de absorção, impossibilidade do monológico, e, desta maneira, potencialização do espaço duplo. Diz Barthes, num pequeno texto chamado "O fantasma, não o sonho", o seguinte: "O sonho me desagrada porque ele nos absorve inteiramente: 0 sonho é monológico; e o fantasma me agrada porque ele permanece concomitante à consciência da realidade (a do lugar onde estou); cria-se assim um espaço duplo, desencaixado" ${ }^{19}$.

Quando, para Policarpo Quaresma, a pátria torna-se uma ausência preenchida por significados que a abrigam de sentido, ele aproxima-a da

\footnotetext{
18 BARRETO, Lima. Triste Fim de Policarpo Quaresma. 17. ed. São Paulo: Ática, 1997. p. 176.

19 BARTHES, Roland. O fantasma, não o sonho. In: Roland Barthes por Roland Barthes. Tradução de: Leyla Perrone-Moisés. São Paulo: Cultrix. p. 94.
} 
ficção. Algo semelhante ocorre no processo psicanalítico, proposto por Jacques Lacan no seminário "O estádio do espelho como formador da função do eu tal como nos é revelada na experiência psicanalítica", em que Lacan aponta para a queda das identificações imaginárias que procuram abrigar com sentido o vazio, a fissura ontológica, que é o sujeito. Desta forma, podemos dizer que as imagens, que alienam o sujeito, cristalizam-no na ficção de ter uma unidade substancial que o faz permanecer, no tempo, idêntico a si mesmo. Assim justamente o que produz a queda das identificações imaginárias levadas até o limite estático de "tu és isto, tu és nada", é um efeito de verdade. Esta verdade, que introduz o fim da análise, lhe revela que o seu ser é nada. Que qualquer tentativa de se afirmar eternamente numa imagem que o defina é uma ficção que o defende do vazio do seu $\operatorname{ser}^{20}$.

A constatação do grau zero das significações parece também ser o tema de Vida e Morte de M. J. Gonzaga de Sá21. Já no início a personagemtítulo nos é apresentada como sendo um amanuense que trabalha na Secretaria dos Cultos, na seção de "alfaias, paramentos e imagens", onde é responsável por decidir coisas irrisórias como "o número de setas que devia ter a imagem de São Sebastião" ou quantas salvas de tiros um bispo deve receber. Exercendo a função de preencher o mundo vazio de significados, criar imagos, fixar um significante, Gonzaga de Sá sempre procura, desta forma, eliminar o grau zero. Sua função única é nomear, atribuir sentidos, porém tal função é descrita pelo narrador como sendo, de fato, insignificante, uma vez que, segundo Barthes, "fazer sentido é muito fácil, toda a cultura de massa o elabora continuamente; suspender o sentido já é uma empresa infinitamente mais complicada, é, se se quiser, uma 'arte'; mas 'aniquilar' o sentido é um projeto desesperado, na proporção de sua impossibilidade" ${ }^{22}$.

Porém, quando não está na Secretaria dos Cultos, a insignificância dos significados preenchidos e fixos parece ser o tema principal das conversas de Gonzaga de Sá com seu amigo Machado, narrador da história. Tal narrativa gira basicamente em torno dum caminhar quase incessante pelas ruas do Rio de Janeiro. Numa das tantas falas que expõe o "grau zero", Gonzaga diz:

20 Cf. LACAN, Jacques. O estádio do espelho como formador da função do eu tal como nos é revelada na experiência psicanalítica. In: Escritos. Rio de Janeiro: Jorge Zahar, 1998. p. 96-103.

${ }_{21}$ Publicado em 1919. O próprio Lima Barreto considera este o seu mais bem acabado romance, segundo Osman Lins. Cf. LINS, Osman. Lima Barreto e o espaço romanesco. São Paulo: Ática, 1976. p. 36.

22 BARTHES, Roland. Literatura e Significação. In: Crítica e Verdade. 3. ed. Tradução de: Leila Perrone-Moisés. São Paulo: Perspectiva, 1999. Coleção Debates. p. 177. 
Nós, os modernos, nos vamos esquecendo que essas histórias de classe, de povos, de raças, são tipos de gabinete, fabricados para as necessidades de certos edifícios lógicos, mas que fora deles desaparecem completamente: _Não são? Não existem. Compreende-se a "esfera", o "cubo", o "quadrado", em geometria; mas fora daí, é em vão querer obtê-los ${ }^{23}$.

Trabalhar para o Estado não impede a Gonzaga tecer uma série de questionamentos que expõe a ausência de conteúdos de certas significações ${ }^{24}$. Aliás, Policarpo Quaresma é subsecretário do arsenal de guerra, também funcionário do Estado. Ambos parecem figurar como "máquinas de guerra", para usarmos um termo que Gilles Deleuze e Félix Guattari descrevem em Mil Platôs. As máquinas de guerra são antagônicas, habitam e ao mesmo tempo agem contra o aparelho de Estado ${ }^{25}$. Contudo, diferente de Gonzaga, Quaresma inicialmente não tem consciência do fracasso que desencadeará seu "engajamento" na procura de uma essência da pátria, ou seja, desconhece a possibilidade de um grau zero, porém chega a ele por fim, operando, no romance, de algum modo, como "devir máquina".

O interessante é que tal noção, de "grau zero", não leva as personagens, não as rebenta, a um fim conclusivo, ou a uma utopia possível $^{26}$. Quaresma, como vimos, morre na prisão, sabendo que tudo que acreditava era nulo; Gonzaga antes de morrer diz a um amigo:

23 BARRETo, Lima. Vida e Morte de M. J. Gonzaga de Sá. In: Prosa Seleta. Rio de Janeiro: Nova Aguilar, 2001. p. 575.

24 Num momento da narrativa, seu amigo Machado, após tantas conversas com Gonzaga, tece um pensamento semelhante aquele de Quaresma. Machado diante de um desfile militar, pensa: "Passaram aos meus olhos lisas faces negras reluzentes, louros cabelos que saíam dos capacetes de cortiça; homens de cor de cobre, olhar duro e forte, raças, variedades e cruzamentos humanos se moviam a uma única ordem, a uma única voz. Tinham, os seus pais, vindo de paragens longínquas e das mais desencontradas regióes do globo. Que motivos ocultos, sob a grosseria dos fatos históricos, explicavam essa estranha impulsão e aquela mesma obediência a um mesmo ideal e a uma mesma ordem?". BARRETO, Lima. Vida e Morte de M. J. Gonzaga de Sá. In: Prosa Seleta. Rio de Janeiro: Nova Aguilar, 2001. p. 619-620.

25 "Do ponto de vista do Estado, a originalidade do homem de guerra, sua excentricidade, aparece necessariamente sob uma forma negativa: estupidez, deformidade, loucura, ilegitimidade, usurpação, pecado... [...]. Porém, restituída a seu meio de exterioridade, a máquina de guerra se revela de uma outra espécie, de uma outra natureza, de uma outra origem. Dir-se-ia que ela se instala entre as duas cabeças do Estado, entre as duas articulações, e que é necessária para passar de uma à outra. Mas justamente, 'entre' as duas, ela afirma no instante, mesmo efêmero, mesmo fulgurante, sua irredutibilidade". E ainda: "Acuado entre os dois pólos da soberania política, o homem de guerra parece ultrapassado, condenado, sem futuro, reduzido ao próprio furor que ele volta contra si mesmo". DELEUZE, Gilles; GUATTARI, Félix. Mil Platôs - Capitalismo e Esquizofrenia. Tradução de: Ana Lúcia de Oliveira (Coord.). São Paulo: Editora 34, 2002. v. 5. p. 12-16.

${ }^{26}$ Em seus romances as personagens não se unem em prol de uma causa ou de uma utopia, como concorda Osman Lins. Lins escreve que em Lima Barreto "as personagens nunca se entrelaçam. Contíguos e sós, integram esta composição anômala e um tanto monstruosa, onde várias unidades isoladas - ignorantes ainda da própria solidão -, apenas se deslocam". LINS, Osman. O espaço romanesco. São Paulo: Ática, 1976. p. 34. 
o que tenho de fato, é aborrecimento, é tédio; sofro em me sentir só; sofro em me ver que organizei um pensamento que não se afina com nenhum...Os meus colegas me aborrecem... [...] Pensei que os livros me bastassem, que eu me satisfizesse a mim próprio... Engano! As noções que acumulei, não as soube empregar nem para a minha glória, nem para a minha fortuna... Não saíram de mim mesmo... Sou estéril e morro estéril... ${ }^{27}$.

A ausência de sentido do mundo não leva as personagens à procura de um pré-sentido, "uma origem do mundo, da vida, dos fatos, anterior ao sentido", como dirá Barthes. Na sua literatura, diferente do seu discurso, Lima Barreto indica, então, que "é preciso atravessar, como o percurso de um caminho iniciático, todo o sentido, para poder extenuá-lo, isentá-lo"28.

Se, por um lado, em sua fala sobre a literatura é comunicado um projeto, é dada uma atribuição cabal à escritura, por outro, na escritura ficcional, pelo menos naquelas que estudamos aqui rapidamente, dá-se somente um levantar de questões, uma tentativa de exposição do "grau zero". Porém, é possível pensar que tal exposição possa, de certa maneira, não estar tão afastada de seu propósito, de sua proposta literária. É provável que Lima Barreto creia que a exposição do "grau zero" pudesse produzir algum efeito no "real", ou provocasse em seus leitores alguma comoção. Contudo, não podemos esquecer que a aparição da "ausência que significa" nos seus romances vincula-se a um certo fracasso, a um desencanto, e não a uma possível formação de qualquer tipo de comunidade futura. $O$ que nos leva a crer que, se há alguma espécie de engajamento na literatura de Lima Barreto, em parte de sua ficção aqui vista, ele pode ser considerado como um "engajamento fracassado", o qual, aliás, é o único possível ${ }^{29}$.

A morte só aparece, em ambas as narrativas, em paralelo à aparição do fantasma, do vazio que significa. A utopia, a busca de uma comunidade encaminha Gonzaga de Sá, logo no início da narrativa, e Policarpo Quaresma, ao final, ao encontro com a morte, com a total solidão, total ausência de comunidade que antes almejavam encontrar. Ora, justamente esta impossibilidade de um encontro constitutivo com a posição de membros, unidades, da comunidade desejada, não viria a ser nada mais do que um

BARRETO, Lima. Vida e Morte de M. J. Gonzaga de Sá. In: Prosa Seleta. Rio de Janeiro: Nova Aguilar, 2001. p. 622.

28 BARTHES, Roland. A isenção de sentido. In: Roland Barthes por Roland Barthes. Tradução de: Leyla Perrone-Moisés. São Paulo: Cultrix. p. 94.

29 Cf. Barthes, "para o escritor, a verdadeira responsabilidade é a de suportar a literatura como um engajamento fracassado, como um olhar fracassado sobre a Terra Prometida do real". BARTHES, Roland. Escritores e Escreventes. In: Crítica e Verdade. 3. ed. Tradução de: Leila Perrone Moisés. São Paulo: Perspectiva, 1999. Coleção Debates. p. 35. 
encontro com aquilo que Blanchot, inspirado em Bataille, chamará de "comunidade inconfessável”?

Encaminada a la muerte, la comunidad "no se encamina como quien se encamina a su obra". "No opera la transfiguración de sus muertos en alguna sustancia o clase de sujeto - patria, suelo natal, nación... falansterio absoluto o cuerpo místico...". Salto algunas frases esenciales, y llego a esta afirmación que es para mí, la más decisiva: "Si la comunidad es revelada mediante la muerte del prójimo, es porque la muerte misma es la verdadera comunidad de seres mortales; su comunión imposible" ${ }^{30}$.

\title{
RESUMO
}

Há nos discursos de Lima Barreto a crença na linguagem, na literatura como desencadeadora de uma comoção que possibilitaria a futura existência de uma comunidade por vir, daí poderíamos apontar uma utopia na sua escritura. Porém, é impossível não ver o desencanto generalizado em muitos de seus enredos. Então cabe uma pergunta: em Lima Barreto há contradição ou coerência entre sua escritura ficcional e a fala sobre a escritura?

Palavras-chave: Lima Barreto; engajamento; grau zero.

\begin{abstract}
In Lima Barreto's discourse there is a belief in language, in literature as release of a commotion that would allow the future existence of a community to come, therefore we could point a utopia in his writing. However, it is impossible not to see the general disenchantment in several of his plots. Henceforth the question: in Lima Barreto: is there a contradiction or a coherence between his fictional writing and his speech about the writing?

Key-words: Lima Barreto; enlisting; degree zero.
\end{abstract}

\section{REFERÊNCIAS}

30 BLANCHOT, Maurice. Comunidad y desobra. In: La comunidad inconfessable. Traducción: Isidro Herrera. Madrid: Arena Libros, 1999. p. 35. 